\title{
The Comparison and Analysis of Three Extraction Methods for Polysaccharides in Purslane
}

\author{
Chunmei GU*, Shu PAN \\ Institute of Food Science and Engineering, Jilin Agricultural University, Changchun, China \\ *Corresponding author: jjnong2008@126.com
}

Received June 27, 2014; Revised July 17, 2014; Accepted July 21, 2014

\begin{abstract}
In this study, three extraction methods of polysaccharides in Purslane were compared and analyzed, and the best method was ascertained. Purslane polysaccharides were extracted using water, ultrasonic and microwave. By the results of single factor experiments and orthogonal experiments, the optimal extracting conditions were selected and then the best extraction method was determined. In order to calculate the extraction yield of polysaccharides, its content were measured by the phenol-sulfuric acid method using glucose as the standard, and then the efficiency of three extraction methods was evaluated. The results showed that the extraction yield of ultrasonic was $35.42 \%$ under the optimal conditions of $60^{\circ} \mathrm{C}, 60 \mathrm{~min}, 1: 20$ and $200 \mathrm{w}$. The extraction yield of microwave method was $32.12 \%$ under the optimal conditions of $3 \mathrm{~min}, 1: 25$ and $500 \mathrm{w}$. The extraction yield of water method was $31.22 \%$ under the optimal conditions of $80^{\circ} \mathrm{C}, 2 \mathrm{~h}, 1: 30$ and 3 times. It could be concluded that ultrasonic method was the best one in these three methods.
\end{abstract}

Keywords: Purslane, polysaccharides, Extraction methods, comparison, analysis

Cite This Article: Chunmei GU, and Shu PAN, "The Comparison and Analysis of Three Extraction Methods for Polysaccharides in Purslane.” Journal of Food and Nutrition Research, vol. 2, no. 7 (2014): 401-405. doi: 10.12691/jfnr-2-7-12.

\section{Introduction}

As a kind of ancient wild plant, Purslane is widely distributed in China. Purslane has a variety of biological activities that have a wide range of pharmacological effects, such as antibacterial [1,2], hypolipidemic, antiaging, anti-inflammatory [3], antioxidative [4], analgesic, and wound healing activities [5,6]. Purslane has been used for thousands of years in traditional Chinese medicine and is a dietetic Chinese medicine which has been officially recognized as a food and a Chinese medicine simultaneously [7]. Known as "vegetable for long life" in Chinese folklore. Purslane is listed in the World Health Organization as one of the most used medicinal plants and it has been given the term 'Global Panacea [8]. For example, it is used in the Arabian Peninsula as an antiseptic, in oral ulcers and in urinary disorders [9]. In addition, this plant has been exhaustively studied in Nigeria and Scotland mainly for its muscle relaxant activity $[10,11,12,13]$. Therefore, it is necessary to study on Purslane.

In recent decades, polysaccharides isolated from plants and animals have attracted a great deal of attention due to their various biological activities [14], for example strong antioxidant, anticancer, anti-microbial and antiinflammatory properties. Because of anti-microbial, polysaccharides can be used for the study of natural preservatives. With the improvement of living standard, people pursue healthy life increasingly. However, the chemical preservatives are used in the processing and production of food [15]. It is known that chemical preservatives ingested for a long time may cause adverse effects on health, even lead to cancer [16]. So the natural preservatives will become the focus of social attention. At the same time, the natural preservatives have strong antimicrobial properties, good water solubility and thermal stability. Therefore, the research for development and utilization of natural preservatives has become a focus of food industry. Nowadays, many extraction methods of polysaccharides have been reported. For example water extraction of polysaccharides was done by Gao et al [17]. Ultrasonic extraction of polysaccharides was done by Qu et al [18] and microwave extraction of polysaccharides was done by Qian and Bi [19]. Because Purslane has the characteristics of convenience, fast growth and low cost [20], the polysaccharides extracted from Purslane are feasible.

In spite of extensive studies on the extraction method of polysaccharides, the comparative analysis about extraction method of Purslane polysaccharides has rarely been studied. This study aims to fill in the knowledge gap for this useful plant. It also lays a foundation for further research of polysaccharides extraction.

\section{Materials and methods}

\subsection{Materials}

Dried Purslane was purchased from pharmacy in Changchun City, Jilin Province, China. Other reagents 
were analytical grade and obtained from Jilin Agriculture University in Changchun City, Jilin Province, China.

\subsection{Sample Preparation}

Dried Purslane plant was defatted in a Soxhlet apparatus with methanol twice, and then filtered the processed sample. The pretreated Purslane was dried at $40^{\circ} \mathrm{C}$ for $12 \mathrm{~h}$ and extracted with distilled water in different conditions using single factor experiments. After centrifugation, the supernatant was concentrated and poured into 3 vol. of anhydrous ethanol for $24 \mathrm{~h}$ to precipitate the crude polysaccharides. According to the standard curve, the absorbance of glucose was determined, and then the content of the polysaccharide was calculated.

\subsection{Determination of Polysaccharides Content}

The polysaccharide content was determined according to the phenol-sulfuric acid method [21]. Standard glucose (10 mg) was dissolved with distilled water $(100 \mathrm{ml})$ and then the standard solution was diluted to different concentrations, and finally pure water was added into the diluted solution. 5\% phenol (1 mL) was added and mixed up. Then sulfuric acid (5 mL) was added and mixed. The absorbance of the solution was measured at $490 \mathrm{~nm}$ with an ultraviolet-visible spectrophotometer, using water as a blank. The standard curve of glucose was: $y=0.0068+$ $0.0169 \mathrm{x}, \mathrm{R}^{2}=0.9927$ ( $\mathrm{x}$ represented the concentration of glucose solution, $\mathrm{y}$ represented absorbance).

\subsection{Water Extraction of Polysaccharides from Purslane}

The factors that influenced water soluble polysaccharides extraction included temperature, extraction time, solid-liquid ratio and extraction times. In single factor experiments, the mixture was extracted using various extraction time $(1 \mathrm{~h}, 2 \mathrm{~h}, 3 \mathrm{~h}, 4 \mathrm{~h}, 5 \mathrm{~h})$, temperature $\left(50^{\circ} \mathrm{C}, 60^{\circ} \mathrm{C}, 70^{\circ} \mathrm{C}, 80^{\circ} \mathrm{C}, 90^{\circ} \mathrm{C}\right)$, solid-liquid ratios $(1: 15,1: 20,1: 25,1: 30,1: 35)$, extraction times $(1,2$, 3, 4, 5 times).

On the basis of single factor experiments, four factors and three levels of L9 $\left(3^{4}\right)$ orthogonal test was selected. The factor levels were shown in Table 1.

Table 1. L9 $\left(3^{4}\right)$ Orthogonal table of water extraction

\begin{tabular}{ccccc}
\hline & & \multicolumn{3}{c}{ Factors } \\
Level & A (temperature) & B (time) & C (solid-liquid ratio) & $1: 20$ \\
\hline 1 & $60^{\circ} \mathrm{C}$ & $2 \mathrm{~h}$ & $1: 25$ & 3 \\
2 & $70^{\circ} \mathrm{C}$ & $3 \mathrm{~h}$ & $1: 30$ & 4 \\
\hline
\end{tabular}

\subsection{Ultrasonic Extraction of Polysaccharides from Purslane}

There are many factors that affect the ultrasonic extraction, such as extraction temperature, ultrasonic time, solid-liquid ratio and ultrasonic power. The mixture was extracted using various extraction temperature $\left(40^{\circ} \mathrm{C}\right.$, $\left.50^{\circ} \mathrm{C}, 60^{\circ} \mathrm{C}, 70^{\circ} \mathrm{C}, 80^{\circ} \mathrm{C}\right)$, time $(30 \mathrm{~min}, 40 \mathrm{~min}, 50 \mathrm{~min}$, $60 \mathrm{~min}, 70 \mathrm{~min})$, Solid-liquid ratios (1:15, 1:20, 1:25, 1:30, 1:35), power levels (100 w, 200w, 300w, 400w, 500w). According to the results of single factor experiments, four factors and three levels of L9 $\left(3^{4}\right)$ orthogonal test was chosen and the level of various factors were shown in Table 2 .

Table 2. L9 $\left(3^{4}\right)$ Orthogonal table of ultrasonic method

\begin{tabular}{ccccc}
\hline & & & Factors & \\
Level & A (temperature) & B (time) & C (solid-liquid ratio) & \\
\hline 1 & $50^{\circ} \mathrm{C}$ & $40 \mathrm{~min}$ & $1: 20$ & $100 \mathrm{w}$ \\
2 & $60^{\circ} \mathrm{C}$ & $50 \mathrm{~min}$ & $1: 25$ & $200 \mathrm{w}$ \\
3 & $70^{\circ} \mathrm{C}$ & $60 \mathrm{~min}$ & $1: 30$ & $300 \mathrm{w}$ \\
\hline
\end{tabular}

\subsection{Microwave Extraction of Polysaccharides from Purslane}

Table 3. L9 $\left(3^{4}\right)$ Orthogonal table of microwave method

\begin{tabular}{cccc}
\hline \multicolumn{4}{c}{ Factors } \\
Level & A (time) & B (solid-liquid ratio) & C (power) \\
\hline 1 & 2 & $1: 20$ & 300 \\
2 & 3 & $1: 25$ & 400 \\
3 & 4 & $1: 30$ & 500 \\
\hline
\end{tabular}

The factors influenced microwave extraction included time, solid-liquid ratio and microwave power. In single factor experiments, the mixture was extracted using various extraction time (1 $\mathrm{min}, 2 \mathrm{~min}, 3 \mathrm{~min}, 4 \mathrm{~min}, 5$ min), solid-liquid ratios $(1: 15,1: 20,1: 25,1: 30,1: 35)$, microwave power levels $(200 \mathrm{w}, 300 \mathrm{w}, 400 \mathrm{w}, 500 \mathrm{w}$, 600w).
On the basis of single factor experiments, three factors and three levels of L9 $\left(3^{4}\right)$ orthogonal test was chosen and the factor levels were shown in Table 3.

\section{Results}

\subsection{The Results of Water Extraction Method}

As can be seen from the results, the extraction yield was increased with the rising of temperature before $70^{\circ} \mathrm{C}$. When the temperature reached $70^{\circ} \mathrm{C}$, there was no significant change. Extraction yield was proportional to extraction time before $3 \mathrm{~h}$ and there was no significant increase after $3 \mathrm{~h}$. When the solid-liquid ratio reached 1:25, the extraction yield was the highest. The extraction times ranges from one to five, but after three times the extraction yield no longer increased. Based on the single factor experiments, the results of orthogonal experiment were shown in Table 4 
Table 4. L9 $\left(3^{4}\right)$ Orthogonal experiment results of water extraction method

\begin{tabular}{|c|c|c|c|c|c|}
\hline Number & Temperature (A) & Time (B) & Solid-liquid ratio(C) & Extraction times (D) & Extraction yield (\%) \\
\hline 1 & A1 & B1 & C1 & D1 & 19.89 \\
\hline 2 & A1 & B2 & C2 & D2 & 21.88 \\
\hline 3 & A1 & B3 & C3 & D3 & 22.63 \\
\hline 4 & A2 & B1 & C2 & D3 & 24.88 \\
\hline 5 & A2 & B2 & C3 & D1 & 20.06 \\
\hline 6 & A2 & B3 & C1 & D2 & 25.13 \\
\hline 7 & A3 & B1 & C3 & D2 & 31.22 \\
\hline 8 & A3 & B2 & C1 & D3 & 19.93 \\
\hline 9 & A3 & B3 & C2 & D1 & 24.39 \\
\hline K1 & 64.40 & 75.99 & 64.95 & 64.34 & \\
\hline K2 & 70.07 & 61.87 & 68.82 & 78.23 & \\
\hline K3 & 75.54 & 72.15 & 71.15 & 67.44 & \\
\hline K1i & 21.47 & 25.33 & 21.65 & 24.45 & \\
\hline K2i & 23.36 & 20.62 & 22.94 & 26.08 & \\
\hline K3i & 25.18 & 24.05 & 23.72 & 22.48 & \\
\hline $\mathrm{R}$ & 1.82 & 4.71 & 2.07 & 3.6 & \\
\hline
\end{tabular}

Note: $\mathrm{R}$ refers to the result of extreme analysis.

Extraction yield $(\%)=($ the content of polysaccharide in the sample / the content of polysaccharide in material $) \times 100$.

From Table 4, the optimum conditions were determined by orthogonal test and extreme difference analysis $(\boldsymbol{R}=$ ${ }_{\max } \mathbf{K}_{\mathbf{i}}-\min _{\mathbf{i n}} \mathbf{K}_{\mathbf{i}}$. According to the value of $\mathrm{R}$ $\left(R_{B}=4.71>R_{D}>R_{C}>R_{A}\right)$, the influence of extraction time on the extraction yield of polysaccharides among the four factors was the biggest. These factors were sequenced by their influence on extraction yield for $\mathrm{B}>\mathrm{D}>\mathrm{C}>\mathrm{A}$. According to the values of $\mathrm{K}_{\mathrm{i}}\left(\mathrm{K}_{\mathrm{A} 3}>\mathrm{K}_{\mathrm{A} 2}>\mathrm{K}_{\mathrm{A} 1}\right.$, $\left.\mathrm{K}_{\mathrm{B} 1}>\mathrm{K}_{\mathrm{B} 3}>\mathrm{K}_{\mathrm{B} 2}, \quad \mathrm{~K}_{\mathrm{C} 3}>\mathrm{K}_{\mathrm{C} 2}>\mathrm{K}_{\mathrm{C} 1}, \quad \mathrm{~K}_{\mathrm{D} 2}>\mathrm{K}_{\mathrm{D} 3}>\mathrm{K}_{\mathrm{D} 1}\right)$, the optimum extraction conditions were $\mathrm{A}_{3} \mathrm{~B}_{1} \mathrm{C}_{3} \mathrm{D}_{2}$, temperature $80^{\circ} \mathrm{C}$, time $2 \mathrm{~h}$, solid-liquid ratio $1: 30$ and extraction times 3 , the extraction yield reached the optimal level.

\subsection{The Results of Ultrasonic Method}

In single factor experiments of ultrasonic-assisted method, the extraction yield of polysaccharides was significantly increased with the increase of temperature before $60^{\circ} \mathrm{C}$. When the temperature exceeded $60^{\circ} \mathrm{C}$, the extraction yield no longer changed. Between $30 \mathrm{~min}$ to 50 min, polysaccharides extraction yield was increased with the increase of time, but when more than 50 minutes, the yield was decreased. When the ultrasonic power reached $200 \mathrm{w}$, the extraction yield reached optimal value. However, when the power exceeded $200 \mathrm{w}$, the extraction yield was deceased significantly. Solid-liquid ratio 1:25 could obtain best extraction yield. According to the single factor experiments, the results of orthogonal experiment were shown in Table 5.

Table 5. L9 $\left(3^{4}\right)$ Orthogonal experiment results of ultrasonic method

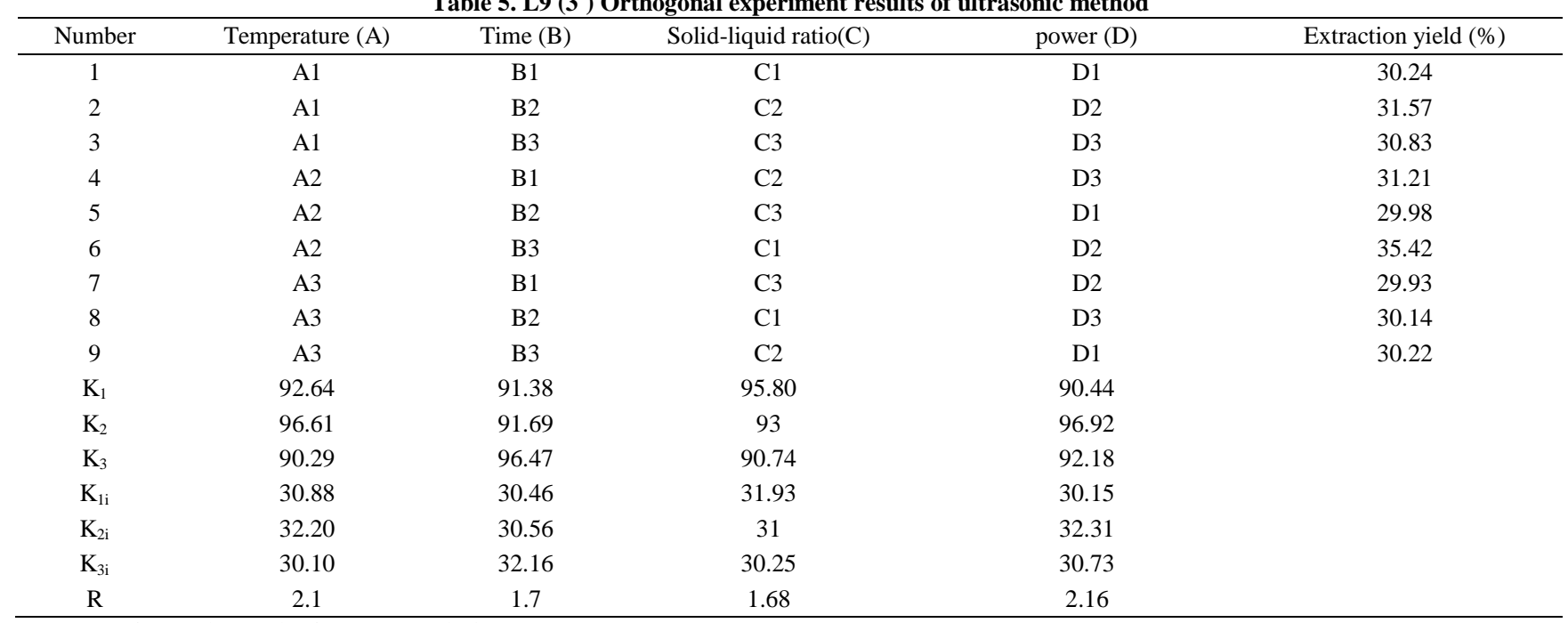

Note:R refers to the result of extreme analysis.

Extraction yield $(\%)=($ the content of polysaccharide in the sample / the content of polysaccharide in material $) \times 100$.

From Table 5, the results were determined by extreme difference analysis $\left(\boldsymbol{R}={ }_{\max } \mathbf{K}_{\mathbf{i}}-{ }_{\min } \mathbf{K}_{\mathbf{i}}\right)$. According to the value of $R\left(R_{D}>R_{A}>R_{B}>R_{C}\right)$, the influence of ultrasonic power on the extraction yield of polysaccharide among the four factors was the biggest. These factors were sequenced by their influence on extraction yield for $\mathrm{D}>\mathrm{A}>\mathrm{B}>\mathrm{C}$. According to the value of $\mathrm{Ki}\left(\mathrm{K}_{\mathrm{A} 2}>\mathrm{K}_{\mathrm{A} 1}>\mathrm{K}_{\mathrm{A} 3}\right.$, $\left.\mathrm{K}_{\mathrm{B} 3}>\mathrm{K}_{\mathrm{B} 2}>\mathrm{K}_{\mathrm{B} 1}, \quad \mathrm{~K}_{\mathrm{C} 1}>\mathrm{K}_{\mathrm{C} 2}>\mathrm{K}_{\mathrm{C} 3}, \quad \mathrm{~K}_{\mathrm{D} 2}>\mathrm{K}_{\mathrm{D} 3}>\mathrm{K}_{\mathrm{D} 1}\right)$, the optimum extraction conditions were $\mathrm{A}_{2} \mathrm{~B}_{3} \mathrm{C}_{1} \mathrm{D}_{2}$ with temperature $60^{\circ} \mathrm{C}$, time $60 \mathrm{~min}$, solid-liquid ratio $1: 20$ and power $200 \mathrm{w}$. Under the conditions the extraction yield reached the optimal level.

\subsection{The Results of Microwave Method}

According to the single factor experiments of microwave-assisted method, the extraction yield was increased before $3 \mathrm{~min}$ and decreased after $3 \mathrm{~min}$. Solidliquid ratio 1:25 was the best ratio in single factor experiments. The power more than $400 \mathrm{w}$ had a negative impact on extraction yield. Based on the single factor experiments, the results of orthogonal experiment were shown in Table 6. 
Table 6. L9 $\left(3^{4}\right)$ Orthogonal experiment results of microwave method

\begin{tabular}{|c|c|c|c|c|}
\hline Number & Time (A) & Solid-liquid ratio (B) & Microwave power(C) & Extraction yield (\%) \\
\hline 1 & $\mathrm{~A} 1$ & B1 & C1 & 21.45 \\
\hline 2 & A1 & B2 & $\mathrm{C} 2$ & 24.18 \\
\hline 3 & A1 & B3 & C3 & 26.73 \\
\hline 4 & A2 & B1 & $\mathrm{C} 2$ & 24.31 \\
\hline 5 & $\mathrm{~A} 2$ & B2 & $\mathrm{C} 3$ & 32.12 \\
\hline 6 & $\mathrm{~A} 2$ & B3 & C1 & 22.77 \\
\hline 7 & A3 & B1 & C3 & 23.08 \\
\hline 8 & A3 & B2 & C1 & 22.11 \\
\hline K1 & 72.36 & 68.84 & 66.33 & \\
\hline K2 & 79.2 & 78.41 & 71.21 & \\
\hline K3 & 67.91 & 72.22 & 81.93 & \\
\hline K1i & 24.12 & 22.95 & 22.11 & \\
\hline K2i & 26.4 & 26.14 & 23.74 & \\
\hline K3i & 22.64 & 24.07 & 27.31 & \\
\hline $\mathrm{R}$ & 3.76 & 3.19 & 5.2 & \\
\hline
\end{tabular}

Note: R refers to the result of extreme analysis.

Extraction yield $(\%)=($ the content of polysaccharide in the sample / the content of polysaccharide in material $) \times 100$.

In Table 6, microwave power had the highest $\mathrm{R}$ value (5.2), the effects of the variables on extraction yields followed the order: microwave power $>$ time $>$ solidliquid ratio. According to the value of $\mathrm{Ki}$, the optimal combinations were $\mathrm{A}_{2} \mathrm{~B}_{2} \mathrm{C}_{3}$ with time 3 min, solid liquid ratio $1: 25$ and power $500 \mathrm{w}$.

Table 7 shows the summary results of these three methods in optimal conditions. Extraction yield of ultrasonic-assisted method was higher than other two methods from Table 7.

Table 7. Comparison the three extraction methods of polysaccharides

\begin{tabular}{cccc}
\hline Method & Water extraction & Ultrasonic extraction & Microwave extraction \\
\hline Extraction temperature & $80^{\circ} \mathrm{C}$ & $60^{\circ} \mathrm{C}$ & - \\
Extraction time & $2 \mathrm{~h}$ & $60 \mathrm{~min}$ & $3 \mathrm{~min}$ \\
Solid-liquid ratio & $1: 30$ & $1: 20$ & $1: 25$ \\
Extraction power & - & $200 \mathrm{w}$ & $500 \mathrm{w}$ \\
Extraction times & 3 & 1 & 1 \\
Extraction yield & $31.22 \%$ & $35.42 \%$ & $32.12 \%$ \\
\hline
\end{tabular}

\section{Discussion}

In recent years, extraction of polysaccharides from Purslane has been studied. It is reported that there were many methods of extracting polysaccharides, such as water extraction, microwave assisted extraction, ultrasonic assisted extraction and some enzymatic methods $[22,23,24]$. However, the comparative research on these methods is not reported until now. So polysaccharides from Purslane were extracted using hot water, ultrasonic and microwave in this study, and according to the results of the orthogonal experiment, these three methods were compared in Table 7 and the best method was determined, which will have an important significance to the research and application of polysaccharides.

Water extraction is a traditional method, and its advantage is mild condition and stable easy to control. The molecules of polysaccharides will not be destroyed by water extraction method. But it should be noted that water extraction of polysaccharides was associated with long extraction time and high temperature. Zhang et al. reported that extraction yield was $9.68 \%$ by water extraction under the conditions of temperature $95^{\circ} \mathrm{C}$, time $60 \mathrm{~min}$, solid-liquid ratio 1:40 [25]. Chen et al. reported that the extraction yield was $12.98 \%$ by water extraction under the conditions of temperature $90^{\circ} \mathrm{C}$, time $120 \mathrm{~min}$, solid-liquid ratio 1:12 [26]. In our study, by the improvement of the previous method, it was found that according to the results of the orthogonal experiment in Table 4, the optimal conditions of water extraction were $80^{\circ} \mathrm{C}, 2 \mathrm{~h}, 1: 30$ and 3 times, and the highest extraction yield was $31.22 \%$. This suggested that our water extraction method had practical significance.

During microwave extraction, it is necessary to optimize the conditions. The results of the microwave orthogonal experiment were shown in Table 6, the optimal process conditions were $3 \mathrm{~min}, 1: 25$ and 500w. Liang reported that the extraction yield was $11.57 \%$ under the conditions $15 \mathrm{~min}, 1: 35$ and 540w [27]. However, in our study, the highest extraction yield was $32.12 \%$ after optimization $3 \mathrm{~min}, 1: 25$ and 500w. In the microwave extraction method, microwave power has a great impact on material. For example, the high power of microwave extraction can cause selective migration of the target compounds from the material to the surroundings at a more rapid rate. Tao and $\mathrm{Xu}$ reported that degradation occurred in the structure of polysaccharides during the microwave heating process [28]. Marshall et al. also studied the possibility of minimizing the disassembly of polysaccharides during microwave extraction [29]. According to the above reports, we could come to a conclusion that the microwave power is an important influence factor of extraction yield.

In the present study, the highest extraction yield was $35.42 \%$ under the optimal ultrasonic conditions $\left(60^{\circ} \mathrm{C}, 60\right.$ min, 1:20, 200w). Yu reported that the extraction yield was $13.28 \%$ under the conditions of ultrasonic $\left(75^{\circ} \mathrm{C}, 55\right.$ min, 1:45, 130w) [30]. Zhang studied that the extraction yield was $11.01 \%$ during ultrasonic extraction $\left(60^{\circ} \mathrm{C}, 30\right.$ min, $1: 25,280 \mathrm{w}$ ) [31]. This could be attributed to the optimal conditions. With the increase of ultrasonic power, the effect of ultrasonic on the cell wall also increases. In 
addition, when the power is too strong, the ultrasonic can lead to the liquid flow too fast. This means that the residence time of material is reduced and extraction yield is also decreased by strong power. On the whole, it is also necessary to optimize the conditions during ultrasonic extraction.

As the saying goes, every coin has two sides. Ultrasonic method and microwave method have the advantages of reducing both extraction time and solvent consumption, which compared with water extraction. At the same time, the disadvantages of ultrasonic method and microwave method are strictly conditions. In addition, compared with the ultrasonic method, the extraction time of microwave method is too short, and the extraction temperature of microwave method cannot be controlled. So by comparing the data and condition of three methods, it was easy to come to a conclusion that ultrasonic method was the best.

\section{Conclusions}

In summary, these three extraction methods have different characteristics. No matter what method, optimization of condition is necessary. When each of these three methods in optimal conditions, ultrasonic method was the best. It lays a foundation for further research of polysaccharides. Further studies on natural preservatives are currently underway.

\section{Acknowledgments}

The authors want to thank Project funded by the Education Department of Jilin Province in China (No. 2013 the sixty-fifth number) for the funding.

\section{Reference}

[1] Lim, Y. Y. and Quah, E. P. L., "Antioxidant properties of different cultivars of Portulaca oleracea,” Food Chemistry, 103 734-740. 2007

[2] Chan, K., Islam, M. W., Kamil, M., Radhakrishnan, R., Zakaria, M. N. and Habibullah, M., "The analgesic and anti-inflammatory effects of Portulaca oleracea L. subsp. Sativa (Haw.) Celak," Journal of Ethnopharmacology, 73. 445-451. 2000.

[3] Dkhil, M. A., Abdel Moniem, A. E., Al-Quraishy, S. and Saleh, R. A., "Antioxidant effect of purslane (Portulaca oleracea) and its mechanism of action," Journal of Medicinal Plants Research, 5. 1563-1589. 2011.

[4] Rashed, A. N., Afifi, F. U. and Disi, A. M., "Simple evaluation of the wound healing activity of a crude extract of Portulaca oleracea L. (growing in Jordan) in Mus musculus JVI-1," Journal of Ethnopharmacology, 88. 131-136. 2003.

[5] Yang, S.C. and Guo, J.F., "Purslane nutrition health care function and its development and utilization, "The food and nutrition of China, 5. 21-23. 2004

[6] Chen, C.J., Wang, W.Y., Wang, X.L, Dong, L.W., Yue, Y.T., Xin, H.L., Ling, C.Q. and Li, M., "Anti-hypoxic activity of the ethanol extract from Portulaca oleracea in mice," Journal of Ethnopharmacology, 124. 246-250. 2009

[7] Niu, G.C., "Progress on chemical compositions and pharmacological function of Portulace oleracea L," Journal of Anhui Agriculture Science, 33, 1090-1092. 2005.

[8] Samy, J., Sugumaran, M. and Lee, K. L. W., "Herbs of Malaysia: An Introduction to the medicinal, culinary, aromatic and cosmetic use of herbs,” Kuala Lumpur: Times Edition. 2004.
[9] Ghazanfar, S.A. "Handbook of Arabian Medicinal Plants," CRC Press, Boca Raton, FL,p. 176. 1994.

[10] Okwuasaba, F., Ejike, C. and Parry, O., "Skeletal muscle relaxant properties of the aqueous extract of Portulaca oleracea," Journal of Ethnopharmacology, 17.139-160. 1986.

[11] Okwuasaba, F., Parry, O. and Ejike, C., "Investigation into the mechanism of action of extracts of Portulaca oleracea,” Journal of Ethnopharmacology, 21. 91-97. 1987.

[12] Parry, O., Okwuasaba, F. and Eijike, C., "Effect of an aqueous extract of Portulaca olearcea leaves on smoothmuscle and rat blood pressure," Journal of Ethnopharmacology, 22. 33-44. 1988.

[13] Parry, O., Marks, J.A. and Okwuasaba, F.K., "The skeletal muscle relaxant action of Portulaca oleracea: role of potassium ions," Journal of Ethnopharmacology, 40. 187-194. 1993.

[14] Xie, J.H., Shen, M.Y., Nie, S.P., Zhao, Q., Li, C. and Xie, M.Y., "Separation of water-soluble polysaccharides from Cyclocarya paliurusby ultrafiltration process," Carbohydrate Polymers, 101. 479-483. 2014.

[15] Zhou, J., Liu, J.W., Fu, J.W. and Hao, L.F., "Purslane polysaccharide extraction and content determination," Chinese herbal medicine, 6. 55-57. 2001.

[16] Li. Y.P., Ye.J., Su.H., Wang, D.J. and Zhou, C.L., "The research progress of purslanepolysaccharide," Food science, 28. 538-540. 2007.

[17] Gao, L., Liu, J., Tian, Y.J. and Hao, Y.J., "The preliminary research on the purslane polysaccharide extraction and purification process," Food research and development, 27. 59-62. 2006.

[18] Qu, X.L., Gao, H.L., Duan, R. and Su, X.H., "The method of ultrasonic extraction of purslane polysaccharides research," Journal of taishan medical college, 2. 119-121. 2009.

[19] Qian, Z.W. and Bi, S.M., "Microwave assisted extraction of purslane polysaccharides research," Guangdong agricultural science, 37, 149-150. 2010.

[20] Zhang, H.Y. and Zheng, L., "The extraction of purslane polysaccharide and antibacterial activity in vitro," Jiangsu agricultural science, 39. 413-415. 2011.

[21] Dubois, M., Gilles, K. A., Hamilton, J. K., Rebers, P. A. and Smith, F., "Colorimetric method for determination of sugars and related substances," Analytical Chemistry, 28 (3). 350-356. 1956.

[22] Mohammad, T. B., Mohammad, H. B. and Farhad, M., "Antitussive effect of Portulaca oleracea L. in guinea pigs," Iranian Journal of Pharmaceutical Research, 3. 187-190. 2004.

[23] Dkhil, M. A., Abdel Moniem, A. E., Al-Quraishy, S. and Saleh, R. A., "Antioxidant effect of purslane (Portulaca oleracea) and its mechanism of action," Journal of Medicinal Plants Research, 5. 1563-1589. 2011.

[24] Rashed, A. N., Afifi, F. U. and Disi, A. M., "Simple evaluation of the wound healing activity of a crude extract of Portulaca oleracea L. (growing in Jordan) in Mus musculus JVI-1," Journal of Ethnopharmacology, 88. 131-136. 2003.

[25] Zhang, Z.F., Lv, G.Y., He, W.Q., Shi, L.G., Pan, H.G. and Fan, L. F., "Effects of extraction methods on the antioxidant activities of polysaccharides obtained from Flammulina velutipes, " Carbohydrate Polymers, 98 (2013). 1524-1531. 2013.

[26] Chen, A.M., Ning, W., Yu, R.H., Li, B.C. and Li, F., "The research of polysaccharide extraction method from Purslane,” Am ino Acid s\& B iotic R esources, 28 (1). 10-11. 2006.

[27] Liang,Y.,.,"Extraction of purslane polysaccharides by microwave assisted process optimization,” Guizhou agricultural science, 40.148-150. 2012

[28] Tao, Y. Z. and Xu, W. L., "Microwave-assisted solubilization and solution properties of hyperbranched polysaccharide," Carbohydrate Research, 343.3071-3078. 2008.

[29] Marshall, L. F., Chau, H. K., Cooke, P. H., Yadav, M. P. and Hotchkiss, A. T., "Physico-chemical characterization of alkaline soluble polysaccharides from sugar beet pulp,” Food Hydrocolloids, 23. 1554-1562. 2009.

[30] Yu, L., "Ultrasonic aided method of extraction of purslane polysaccharides," The north garden, 5, 36-38. 2011

[31] Zhang, Y.M., Li,B.C., Zhu, L.P., Dai, W.F. and Fan, J.H., "Polysaccharide chemistry and biological research progress," Journal of kunming university of science and technology, 28,140148. 2003.

[32] Tian, G.H., Liu, C.F. and Lai, P.H., "Purslane experimental study on the ultrasonic extraction and activity of polysaccharides," Food research and development, 128. 7-10. 2007. 